\title{
RPS4YI Promotes High Glucose-Induced Endothelial Cell Apoptosis and Inflammation by Activation of the p38 MAPK Signaling
}

\author{
Yuan Chen ${ }^{1, *}$ \\ Yiheng Chen ${ }^{2, *}$ \\ Chonghui Tang ${ }^{3}$ \\ Qian Zhao' \\ Tailin Xu' \\ Qi Kang' \\ Bin Jiang ${ }^{2}$ \\ Li Zhang ${ }^{4}$
}

'Department of Endocrinology, The First People's Hospital of Zunyi, Zunyi,

Guizhou, 563000, People's Republic of

China; ${ }^{2}$ Department of Hand and Plastic

Surgery, The Second Affiliated Hospital of

Wenzhou Medical University, Wenzhou,

Zhejiang, 325000, People's Republic of

China; ${ }^{3}$ Department of Neurosurgery,

Affiliated Cixi Hospital, Wenzhou Medical

University, Wenzhou, Zhejiang, 315300,

People's Republic of China; ${ }^{4}$ Department of Neurosurgery, China-Japan Friendship Hospital, Beijing, 100029, People's

Republic of China

*These authors contributed equally to this work
Correspondence: Li Zhang

Department of Neurosurgery, ChinaJapan Friendship Hospital, No. 2 Yinghua East Road, District of Chaoyang, Beijing, 100029, People's Republic of China Email ftzy73129@sina.com

\begin{abstract}
Aim: Endothelial dysfunction is a key pathological basis for diabetes mellitus complications, including diabetic nephropathy, diabetic retinopathy, and diabetic cardiomyopathy. This study aimed to reveal the functional role of ribosomal protein S4 Y-linked 1 (RPS4Y1) in endothelial dysfunction.
\end{abstract}

Methods: Human umbilical vein endothelial cells (HUVECs) were subjected to high glucose. The expression of RPS4Y1 in cells was overexpressed or silenced by plasmid or siRNA transfection. MTT assay, flow cytometry, JC-1 probe, scratch test, tube formation, and ELISA were conducted to assess the effects of RPS4Y1 on cell. Western blot was performed to assay the downstream signaling of RPS4Y1. The inhibitors of p38, ERK, and Jnk were used to treat cells to validate the involvement of them in RPS4Y1-mediated endothelial dysfunction.

Results: RPS4Y1 was upregulated in HUVECs in response to high glucose in both doseand time-dependent manners. Overexpression of RPS4Y1 induced viability loss, apoptosis, and inflammation, but inhibited cell migration and tube formation. Silence of RPS4Y1 impacted these aspects in a contrary trend. The phosphorylation of p38 rather than ERK and Jnk was activated by RPS4Y1. In addition, the dysfunction of HUVECs mediated by RPS4Y1 was attenuated by SB203580 (a specific inhibitor of p38 signaling).

Conclusion: The highly expressed RPS4Y1 in endothelial cells may contribute to high glucose-induced dysfunction through regulating p38 MAPK signaling. RPS4Y1 might be a potential therapeutic target for treating diabetes mellitus complications.

Keywords: RPS4Y1, HUVEC, diabetes mellitus, high glucose, p38 MAPK signaling

\section{Introduction}

Diabetes mellitus is a kind of metabolic disorder characterized by chronic hyperglycemia that is mainly caused by the defects of insulin secretion and/or use. As estimated by the International Diabetes Federation (IDF), there are approximately 300 million patients with diabetes mellitus around the world, and $80 \%$ of them are in low-income countries. ${ }^{1}$ Several genetic and lifestyle factors, like age, pregnancy, smoking, and obesity are thought to be involved in the pathogenesis of diabetes mellitus. ${ }^{2}$ Along with the increase in aging and obesity of population, the incidence of diabetes mellitus is increased greatly in the recent decades. ${ }^{2,3}$

Endothelial cells are a layer of highly differentiated flat cells located in the inner wall of blood vessels and lymphatics. Vascular endothelium consisting of endothelial cells is the main barrier to maintaining vascular permeability and is the central target of metabolites. The deleterious impacts of blood high glucose are found in 
various kinds of cells, including endothelial cells. ${ }^{4}$ In response to high glucose, the synthesis of diacylglycerol is promoted, protein kinase $\mathrm{C}$ is activated, and the level of advanced glycation end products is increased, which further induces the reactive oxygen species (ROS) and leads to endothelial cell dysfunction. ${ }^{5}$ The dysfunction of endothelial cells is a key pathological basis for diabetes mellitus complications, including diabetic nephropathy, ${ }^{6}$ diabetic retinopathy, ${ }^{7}$ and diabetic cardiomyopathy. ${ }^{8}$ Therefore, maintaining the normal endothelial function has been considered as an effective therapeutic intervention in patients with diabetes mellitus. ${ }^{5}$

Ribosomal protein S4 Y-linked 1 (RPS4Y1) codifies for ribosomal protein $\mathrm{S} 4$ that locates at chromosome p11.31. ${ }^{9}$ RPS4Y1 is ubiquitously expressed and it plays a significant role in correct development. ${ }^{10,11}$ It has been reported that RPS4Y1 together with RPS4Y2 have essential roles in Turner syndrome. ${ }^{12}$ RPS4Y1 was highly expressed in the placental samples of preeclampsia patient, and RPS4Y1 contributed to the inhibition of trophoblast cell migration and invasion. ${ }^{13}$ RPS4Y1 was also found to be expressed in endothelial cells, ${ }^{14}$ but its function in endothelial cells under the event of diabetes mellitus is still unknown.

In the present study, we aimed to reveal the functional roles of RPS4Y1 in endothelial cells under high glucose conditions, which was widely conducted to mimic the diabetes mellitus microenvironment. ${ }^{15}$ The preliminary underlying mechanism of RPS4Y1 was also investigated. The findings of this work suggest evidence of gene target therapy in treating diabetes mellitus complications.

\section{Materials and Methods HUVECs Culture}

Human umbilical vein endothelial cells (HUVECs) were obtained from American Type Culture Collection (ATCC, Manassas, VA, USA). Cells were cultured in endothelial cell growth medium (Gibco, Rockville, MD, USA) containing 5 $\mathrm{mM}$ glucose. For complete culture medium, 10\% fetal bovine serum (Gibco) was supplemented, and cells were maintained in a humidified incubator with $5 \% \quad \mathrm{CO}_{2}$ at $37^{\circ} \mathrm{C}$. For high glucose culture, additional glucose (Gibco) with different concentrations $(5,15,25$, and $30 \mathrm{mM})$ was added in the culture medium. The cells were treated with high glucose for $0,4,8$, or $24 \mathrm{~h}$. To eliminate the adverse effects of high glucose on cells, we added different concentrations of mannitol (Sigma-Aldrich, St. Louis, MO, USA) to balance the osmotic pressure in each group.

To inhibit the p38, ERK, and Jnk signaling, $30 \mu \mathrm{M}$ SB203580 (MedChemExpress, Monmouth Junction, NJ, USA), $30 \mu \mathrm{M}$ PD98059 (MedChemExpress), or $10 \mu \mathrm{M}$ SP600125 (MedChemExpress) were used to treat cells for $24 \mathrm{~h}$, respectively.

\section{Cell Transfection}

RPS4Y1 overexpression plasmid and RPS4Y1 siRNA (5'GGAAAGGGCATTCGACTTACT-3') were purchased from Ribobio (Guangzhou, China). The empty vector and scrambled siRNA were used as blank controls. For transfection, HUVEC cells with high confluence (60-70\%) were collected into the culture medium and allowed to be cultured in the humidified incubator at $37^{\circ} \mathrm{C}$ overnight. Subsequently, the corresponding plasmid or siRNA was transfected into the cells by Lipofectamine 2000 (Invitrogen, Carlsbad, CA, USA) according to the manufacturer's instructions. After $48 \mathrm{~h}$, cells were collected for subsequent experiments.

\section{MTT}

Cell viability was measured using an MTT assay. In brief, the treated HUVECs were added into 96-well plates with a concentration of $5 \times 10^{3}$ cells per well. Following 12 $\mathrm{h}$ of incubation, $20 \mu \mathrm{L}$ MTT solution (Solarbio, Beijing, China) was added for an additional $4 \mathrm{~h}$ of incubation at $37^{\circ} \mathrm{C}$. After the removal of the supernatant, $100 \mu \mathrm{L}$ DMSO (Sigma-Aldrich) was used to dissolve the purple formazan. The absorbance value of each well at $490 \mathrm{~nm}$ was detected under a microplate reader (Bio-Rad, Hercules, CA, USA).

\section{Flow Cytometry}

Cell apoptosis was detected by Annexin V-FITC Apoptosis Detection kit (BD Biosciences, CA, USA) according to the manufacturer's instructions. Briefly, the treated HUVECs were harvested, followed by incubation with $10 \mu \mathrm{L}$ Annexin V-FITC for $10 \mathrm{~min}$ and PI for 5 $\min$ in the dark. Ultimately, the apoptosis of cell $(5 \times$ $10^{4}$ per sample) was calculated by using the flow cytometer (BD Biosciences).

\section{Measurement of Mitochondrial Membrane Potential $(\Delta \psi \mathrm{m})$}

The $\Delta \psi \mathrm{m}$ was detected by the JC-1 probe (Beyotime, Shanghai, China) based on the manufacturer's instruction. In brief, $5 \times 10^{5}$ HUVECs following treatment were 
harvested and incubated with JC-1 solution for $20 \mathrm{~min}$ at $37^{\circ} \mathrm{C}$. The HUVECs were rinsed with JC-1 buffer, and the fluorescence intensity was measured under a fluorescence microscope (Olympus, Tokyo, Japan).

\section{Scratch Test}

Following transfection and high glucose treatment, $5 \times 10^{5}$ HUVECs were collected and seeded in the 6-well culture plates, which were pre-marked on the back of the plates. A $20 \mu \mathrm{L}$ pipette was used to create a scratch in the cultures. The non-adherent cells were removed by three washes of PBS, and the cultures were maintained at $37^{\circ} \mathrm{C}$ for 24 or $48 \mathrm{~h}$. The scratch was photographed, and the wounded distance was calculated.

\section{Tube Formation Assay}

Matrigel (BD Biosciences) was pre-cold at $4^{\circ} \mathrm{C}$ overnight and then mixed with a serum-free culture medium (1:3). The mixture was added to 24 -well plates $(300 \mu \mathrm{L}$ per well), and the HUVECs following transfection and high glucose treatment were added. After $24 \mathrm{~h}$ of incubation at $37^{\circ} \mathrm{C}$, the cultures were photographed. Tube/cord lengths of capillary-like structures were calculated by using the ImageJ software (National Institutes of Health, USA).

\section{Enzyme-Linked Immunosorbent Assay (ELISA)}

Following transfection and high glucose treatment, the supernatant of HUVECs was collected and used for ELISA assay. The levels of IL- $1 \beta$, IL- 6 , TNF- $\alpha$, and IL- 8 were measured by the commercial analyzing kits (Abcam, Cambridge, MA), according to the manufacturer's instruction.

\section{Real-Time Quantitative RT-PCR}

Total RNA was isolated from HUVECs using an RNA simple total RNA kit (Tiangen, Beijing, China). Reverse transcription was performed by the Fast Quant RT Kit (Tiangen) according to the manufacturer's instructions. Quantitative real-time PCRs were performed using the Super Real PreMix Plus SYBR Green (Tiangen) on a QuantStudio 6 Flex system. The relative quantification of RPS4Y1 gene was calculated using $2-\Delta \Delta \mathrm{Ct}$ method. $\beta$-actin severed as the internal control. The primer sequences used in the RTPCR procedure are listed as follows. RPS4Y1, 5'-
CCCTGCTGGATTCATGGATGT-3' (forward), 5'GCTGCTACTGCAATTT AGCCAC-3' (reverse); $\beta$ actin, 5'-GATTCCTATGTGGGCGACGA-3' (forward), 5'-AGGTCTCAAACATGATCTGGGT-3' (reverse).

\section{Western Blot}

HUVECs were lysed with RIPA buffer (Beyotime, Shanghai, China), and total protein was obtained. The protein concentration was measured by using the BCA protein assay kit (Tiangen). After processing with loading buffer, proteins $(50 \mu \mathrm{g})$ were subjected to SDS/PAGE (10$12 \%$ gels), and then transferred to PVDF membranes (Millipore, Billerica, MA, USA). The blot was blocked with $5 \%$ nonfat milk for $2 \mathrm{~h}$ at room temperature and incubated with primary antibodies overnight at $4^{\circ} \mathrm{C}$. The primary antibodies used were listed as following: RPS4Y1 (1:1000; RayBiotech, Norcross, GA, USA), NOX-4 (1:1000; Abcam), IL-1 $\beta$ (1:1000; Abcam), IL-6 (1:1000; Abcam), TNF- $\alpha$ (1:1000; Abcam), p38 (phospho Y182, 1:1000; Abcam), ERK1/2 (1:1000; Abcam), ERK1/2 (phospho T202/T185, 1:1000; Abcam), Jnk1/2 (1:1000; Abcam), Jnk1/2 (phosphor T183/Y185), $\beta$-actin (1:1000; Abcam), IL-8 (1:1000; Biorbyt, San Francisco, CA, USA), and p38 (1:500; Biorbyt). After washing, blots were incubated with appropriate HRP-conjugated secondary antibody (1:1000; Abcam) for $2 \mathrm{~h}$. The protein bands were visualized and revealed by chemiluminescence using an ECL detection kit (Millipore).

\section{Statistical Analysis}

All the assays were performed at least three times independently. Data are presented as mean \pm standard deviation. Statistical significance was assessed by Student's $t$-test or one-way ANOVA. $p<0.05$ was considered to be a significant difference.

\section{Results}

\section{RPS4Y I Was Highly Expressed in HUVECs in Response to High Glucose}

First, the expression changes of RPS4Y1 in HUVECs following high glucose treatment were measured. In order to eliminate the adverse effects of osmotic pressure caused by high glucose on cells, the same dose of mannitol was used. ${ }^{16}$ Glucose-sensitive protein NOX-4 was tested as a positive control. ${ }^{17}$ As seen in Figures 1A and B, the mRNA $(p<0.05)$ and protein levels of RPS4Y1 were remarkably increased by $24 \mathrm{~h}$ of glucose treatment in a dose-dependent manner. In 
A

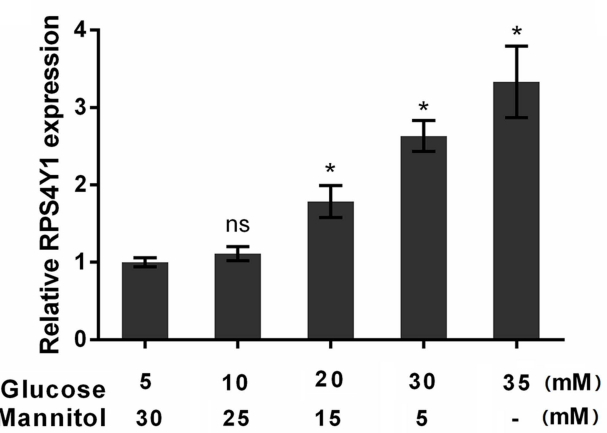

B

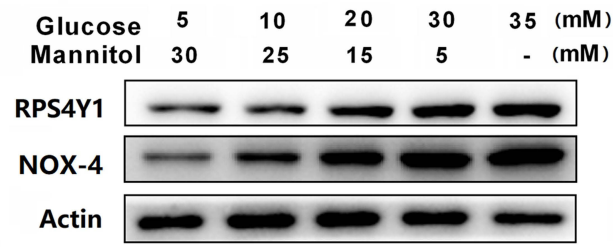

C

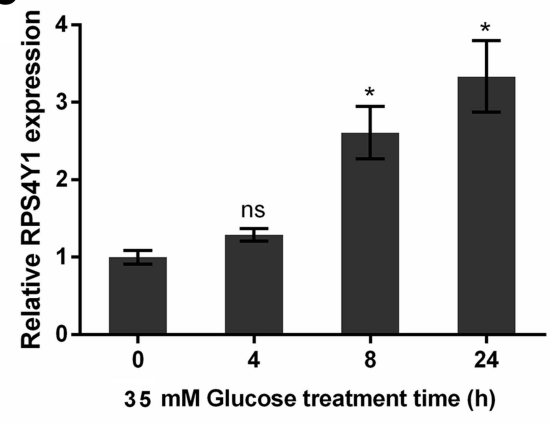

D

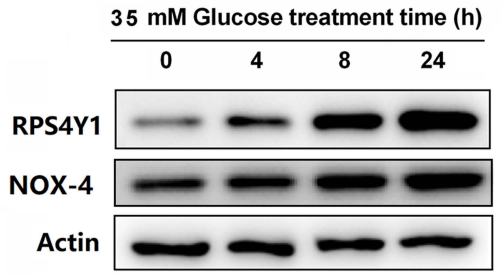

Figure I RPS4YI was highly expressed in HUVECs in response to high glucose. (A) HUVECs were treated by various concentrations of glucose for $24 \mathrm{~h}$. The same dose of mannitol was added to eliminate the adverse effects of osmotic pressure caused by high glucose on cells. mRNA level of RPS4YI was measured by qRT-PCR. (B) Protein level of RPS4YI was measured by Western blot. (C) HUVECs were treated by $35 \mathrm{mM}$ glucose for $0-24 \mathrm{~h}$. mRNA level of RPS4YI was measured by qRT-PCR. (D) Protein level of RPS4YI was measured by Western blot; ${ }^{*} \mathrm{p}<0.05$ vs the controls $(30 \mathrm{mM}$ mannitol $+5 \mathrm{mM}$ glucose or $0 \mathrm{~h}$ groups).

Abbreviation: ns, no significant.

addition, the mRNA $(\mathrm{p}<0.05)$ and protein levels of RPS4Y1 was elevated by $35 \mathrm{mM}$ glucose in a time-dependent manner (Figures 1C and D). HUVECs were treated by $35 \mathrm{mM}$ glucose for $24 \mathrm{~h}$ in the following studies.

\section{RPS4YI Induced the Apoptosis of HUVECS}

RPS4Y1 overexpression plasmid and the specific siRNA against RPS4Y1 were, respectively, transfected into HUVECs to see the functional impacts of RPS4Y1. As seen in Figures $2 \mathrm{~A}$ and $\mathrm{B}$, mRNA $(\mathrm{p}<0.05)$ and protein levels of RPS4Y1 were elevated by transfection with the overexpression plasmid, while it was silenced by the siRNA transfection. Overexpression of RPS4Y1 significantly inhibited cell viability, while RPS4Y1 silence promoted cell viability $(\mathrm{p}<0.05$, Figure 2C). RPS4Y1 overexpression significantly induced cell apoptosis $(\mathrm{p}<0.05)$, but RPS4Y1 silence failed to inhibit apoptosis ( $>0.05$, Figure 2D), possibly due to the apoptosis being already very low. JC-1 staining results showed that RPS4Y1 overexpression induced mitochondrial depolarization, while RPS4Y1 siRNA inhibited mitochondrial depolarization $(p<0.05$, Figure 2E).

\section{RPS4YI Enhanced the Dysfunction and Inflammation in HUVECs}

The function and inflammation of HUVECs following transfection were then tested. Figures $3 \mathrm{~A}$ and $\mathrm{B}$ showed that the migrating and tube formation capacities of HUVECs were inhibited by RPS4Y1 overexpression, while promoted by RPS4Y1 silence $(p<0.05)$. In addition, RPS4Y1 overexpression significantly increased the levels of pro-inflammatory cytokines, including IL-1 $\beta$ (Figure 3C), IL-6 (Figure 3D), TNF- $\alpha$ (Figure 3E), and IL-8 (Figure 3F). The protein expression of IL-1 $\beta$, IL- 6 , TNF- $\alpha$, and IL- 8 was increased by RPS4Y1 overexpression (Figure 3G). Silence of RPS4Y1 impacted those proteins in a contrary trend.

\section{RPS4YI Enhanced the Apoptosis of HUVECs Induced by High Glucose}

Data in Figure 4A displayed that transfection of HUVECs with RPS4Y1 overexpression plasmid significantly accelerated the viability loss induced by high glucose, while RPS4Y1 siRNA attenuated the viability loss $(p<0.05)$. The apoptosis induced by high glucose was further accelerated by RPS4Y1 overexpression plasmid but attenuated by RPS4Y1 siRNA ( $<<0.05$, Figure $4 B)$. In line with this, JC-1 staining results indicated that the mitochondrial 
A

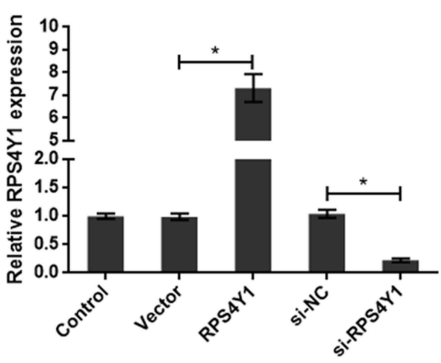

D
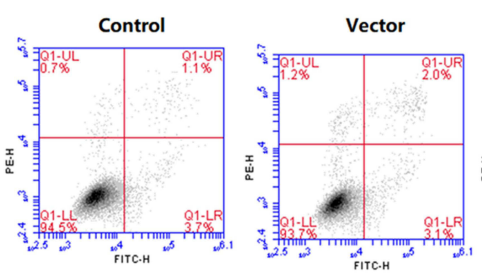

E
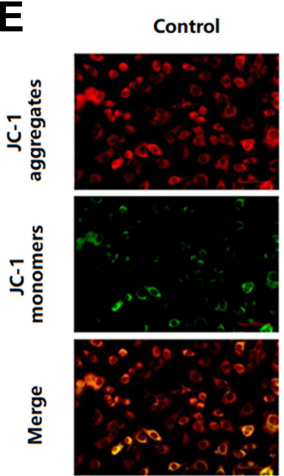

B

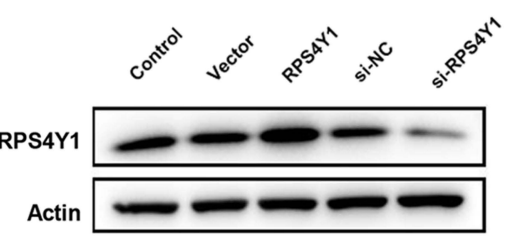

C

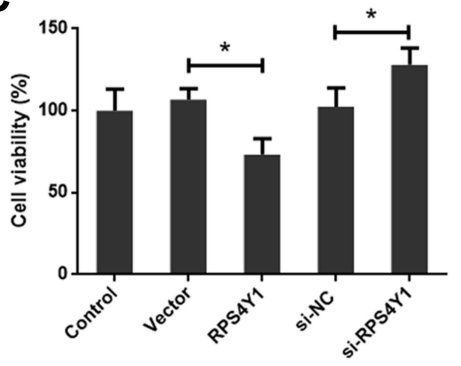

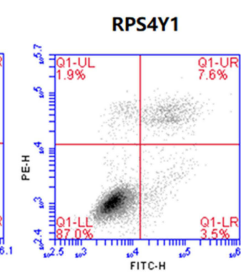

RPS4Y1
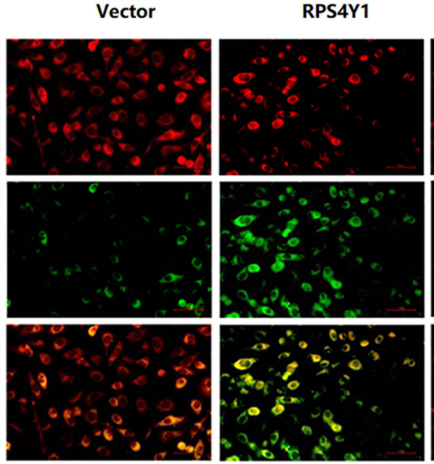
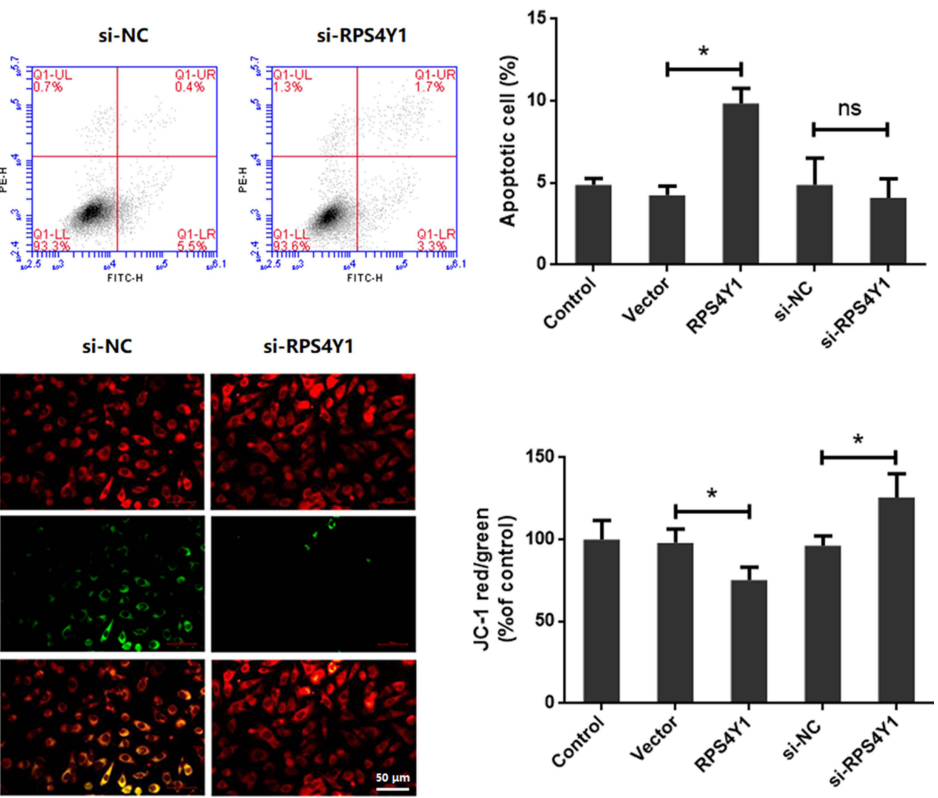

si-RPS4Y1

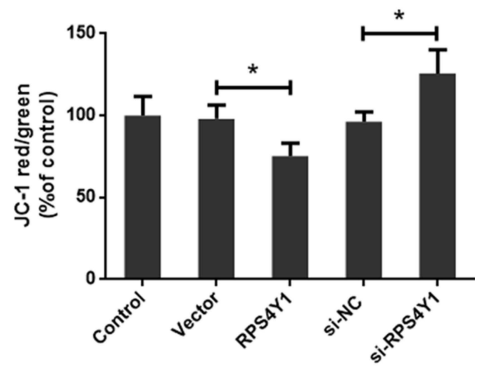

Figure 2 RPS4YI induced HUVECs apoptosis. HUVECs were transfected with RPS4YI overexpression plasmid, RPS4YI siRNA or the negative controls (empty vector and si-NC). (A) mRNA level of RPS4YI was measured by qRT-PCR. (B) Protein level of RPS4YI was measured by Western blotting. (C) The viability, (D) apoptosis, and (E) $\Delta \psi \mathrm{m}$ were detected by MTT, flow cytometry, and JC-I probe, respectively. ${ }^{*} \mathrm{p}<0.05$ vs the indicated group.

depolarization induced by high glucose was enhanced by RPS4Y1 overexpression plasmid but attenuated by RPS4Y1 siRNA ( $<<0.05$, Figure 4C).

\section{RPS4YI Enhanced the Dysfunction and Inflammation in HUVECs Induced by High Glucose}

The migrating capacity of HUVECs was analyzed by scratch test. As seen in Figure 5A, high glucose significantly inhibited the wound closure $(\mathrm{p}<0.05)$. Transfection of cells with RPS4Y1 overexpression plasmid further inhibited the wound closure, while RPS4Y1 siRNA significantly promoted the wound closure $(p<0.05)$. In addition, the tube formation capacity of HUVECs was inhibited by high glucose and further aggravated by RPS4Y1 overexpression plasmid $(\mathrm{p}<0.05$, Figure 5B). RPS4Y1 siRNA impacted the tube formation in a contrary trend $(\mathrm{p}<0.05)$.
The concentration of pro-inflammatory cytokines in the supernatant of HUVECs following transfection and high glucose treatment was analyzed. The IL-1 $\beta$ (Figure $5 \mathrm{C}$ ), IL-6 (Figure 5D), TNF- $\alpha$ (Figure 5E), and IL-8 (Figure 5F) levels were significantly elevated by high glucose (all $p<0.05$ ). Transfection of cells with RPS4Y1 overexpression plasmid further increased the levels of these cytokines, while RPS4Y1 siRNA decreased the levels $(\mathrm{p}<0.05)$. Protein expression of IL-1 $\beta$, IL-6, TNF- $\alpha$, and IL-8 induced by high glucose was also enhanced by RPS4Y1 overexpression plasmid, while suppressed by RPS4Y1 siRNA (Figure 5G).

\section{RPS4Y I Activated p38 MAPK Signaling to Mediate HUVECs Apoptosis}

MAPK is a widely studied signaling that plays a vital role in regulating endothelial cell survival, apoptosis, inflammation, and dysfunction. ${ }^{18,19}$ By performing Western blot analysis, the phosphorylation of p38 was found to be 

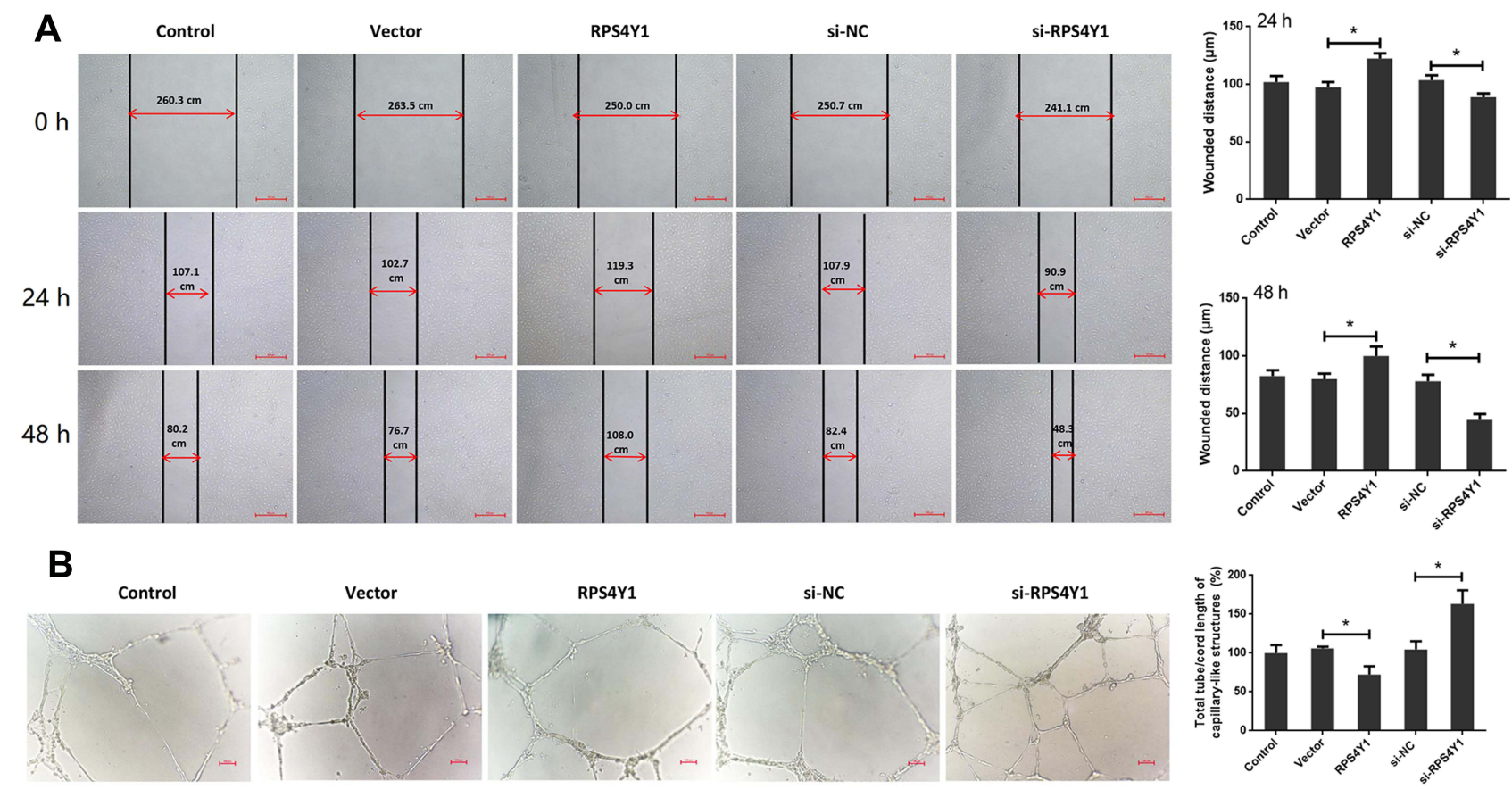

Si-RPS4Y1
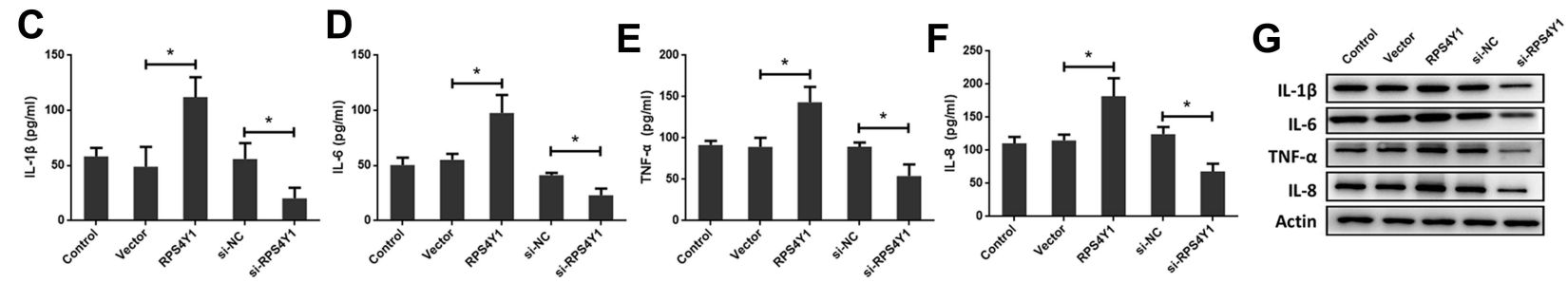

Figure 3 RPS4YI induced the dysfunction and inflammation of HUVECs. HUVECs were transfected with RPS4YI overexpression plasmid, RPS4YI siRNA or the negative controls (empty vector and si-NC). (A) The migration and (B) tube formation of cells were analyzed by using scratch test and Matrigel gel. (C) IL-I $\beta$, (D) IL-6, (E) TNF- $\alpha$, and (F) IL-8 were analyzed by ELISA. (G) The protein expression of these cytokines was measured by Western blot. *p<0.05 vs the indicated group.

promoted by RPS4Y1 overexpression plasmid, while suppressed by RPS4Y1 siRNA (Figure 6A). Both RPS4Y1 overexpression plasmid and RPS4Y1 siRNA showed no obvious effects on the phosphorylation of ERK and Jnk.

For further investigation, the specific inhibitors of $\mathrm{p} 38$ (SB203580), ERK (PD98059) and Jnk (SP600125) were used. Figure $6 \mathrm{~B}$ shows that the phosphorylation of $\mathrm{p} 38$, ERK and Jnk was respectively inhibited by SB203580, PD98059 and SP600125. SB203580 significantly attenuated RPS4Y1-induced apoptosis $(p<0.05$, Figure 6C), while PD98059 and SP600125 showed no significant impacts on apoptosis $(\mathrm{p}>0.05)$.

\section{RPS4YI Activated p38 MAPK Signaling to Mediate HUVECs Dysfunction and Inflammation}

It was shown that SB203580 significantly attenuated the impacts of RPS4Y1 overexpression on HUVECs migration $(\mathrm{p}<0.05$, Figure 7A) and tube formation $(\mathrm{p}<0.05$, Figure 7B). Both PD98059 and SP600125 had no significantly impacts on HUVECs migration and tube formation $(\mathrm{p}>0.05)$.

Treating HUVECs with SB203580 also significantly attenuated RPS4Y1 induced the increase of IL-1 $\beta$ (Figure 7C), IL-6 (Figure 7D), TNF- $\alpha$ (Figure 7E), and IL-8 (Figure 7F) levels (all p<0.05). PD98059 and SP600125 could not change the concentration of these cytokines in the supernatant $(\mathrm{p}>0.05)$.

\section{Discussion}

High blood glucose is one of the main causal factors of endothelial dysfunction in diabetes mellitus, ${ }^{5}$ thereby setting the stage for long-term complications. ${ }^{20}$ In the present study, high glucose was used to treat HUVECs for $24 \mathrm{~h}$ to mimic an in vitro model of endothelial dysfunction. It was found that high glucose induced a significant cell death and inflammation, and suppressed the migrating and tube formation capacities of HUVECs, which was in line with 


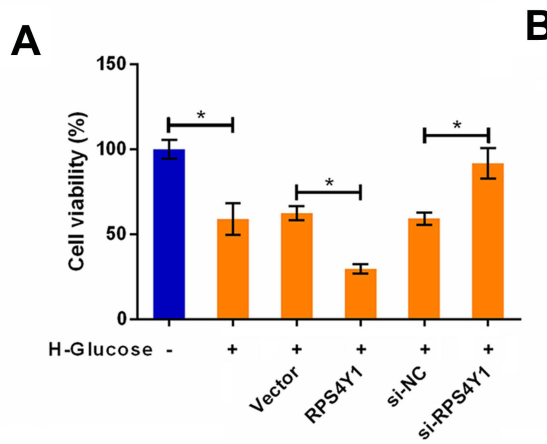

B
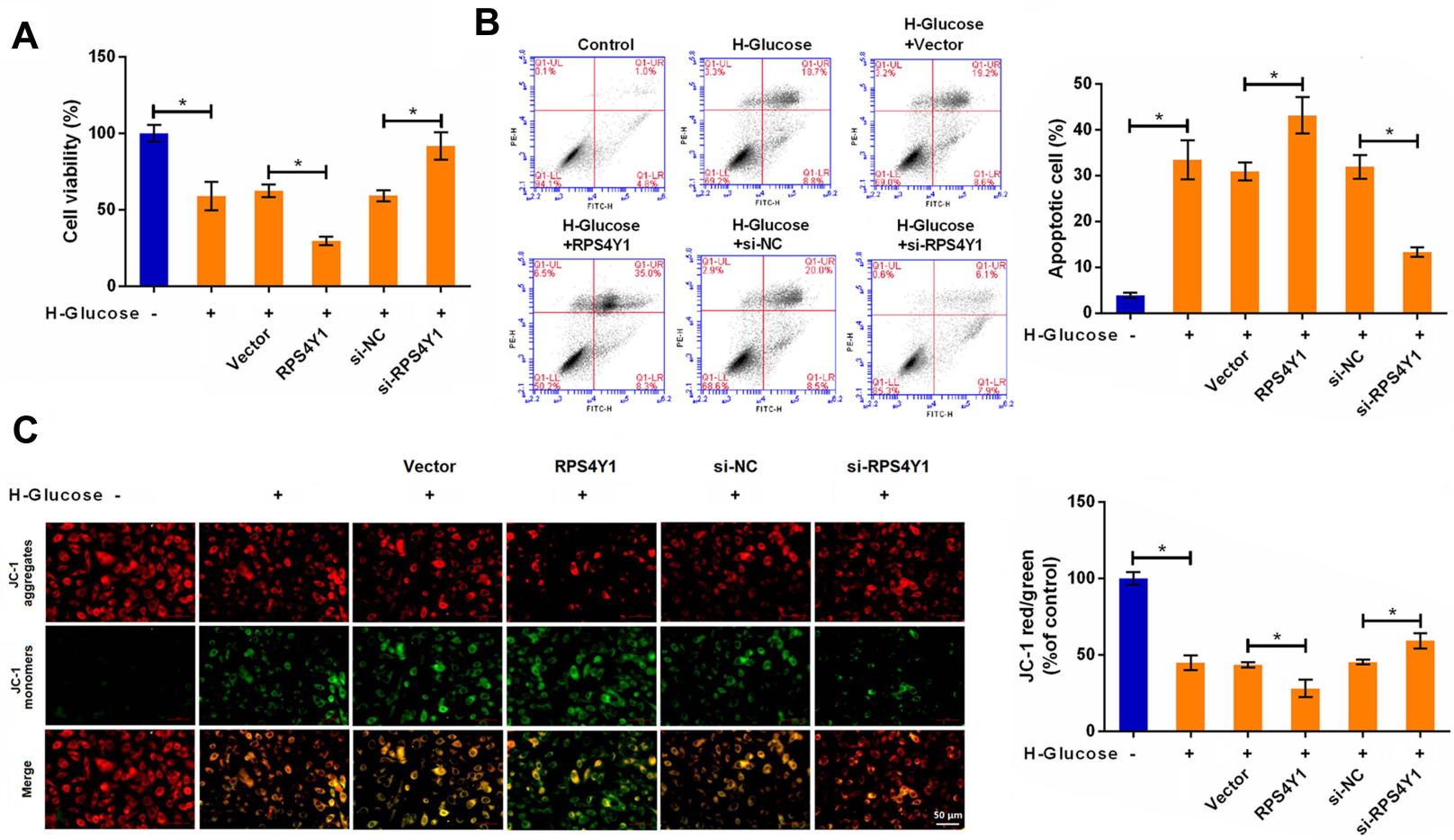

Figure 4 RPS4YI enhanced the apoptosis of HUVECs induced by high glucose. HUVECs were transfected with RPS4YI overexpression plasmid, RPS4YI siRNA or the negative controls (empty vector and si-NC). Following transfection, cells were treated by $35 \mathrm{mM}$ glucose for $24 \mathrm{~h}(\mathrm{H}-\mathrm{Glucose}$ group). (A) The viability, (B) apoptosis, and (C) $\Delta \psi \mathrm{m}$ were detected by MTT, flow cytometry, and JC-I probe, respectively. ${ }^{*} \mathrm{p}<0.05$ vs the indicated group.

a mass of previous studies. ${ }^{15,16,21}$ Further studies demonstrated that RPS4Y1 was up-regulated in response to high glucose in HUVECs. The elevated RPS4Y1 expression in HUVECs contributed to viability loss, mitochondrialdependent apoptosis, and inflammation induced by high glucose. RPS4Y1 overexpression, on the other hand, impaired the normal function of HUVECs, including the migrating and tube-formation capacities. On the contrary, silence of RPS4Y1 impacted these aspects in a contrary trend. p38 signaling pathway, rather than ERK and Jnk signaling, was activated by RPS4Y1. We further revealed that RPS4Y1 accelerated high glucose induced endothelial dysfunction possibly via regulating p38 signaling.

Ribosome protein genes are well-known structural components of the ribosome, which is the essential machinery of protein translation. In mammalian cells, the regulated production of ribosome-related genes is important in all organisms to maintain a functional proteome. $^{22,23}$ In addition, ribosome-related genes are involved in extra-ribosomal functions, like DNA repair, apoptosis and cellular homeostasis. ${ }^{24}$ In response to high glucose, the ribosome-related genes, as a kind of stressresponsive genes, are up- or down-regulated. ${ }^{25}$ The ribosome-related genes then contribute to the regulation of various signaling pathways through direct binding with the main components or the upstream factors of signaling pathways. For example, the silence of ribosomal protein $\mathrm{S} 3$ inhibited NF- $\kappa \mathrm{B}$ signaling through binding to the p65 subunit of the NF- $\kappa \mathrm{B}$ complex via its $\mathrm{KH}$ domain. $^{26}$ Ribosomal protein L11 activated p53 signaling by inhibiting oncoprotein MDM2. ${ }^{27}$ Through mediation of the diverse signaling pathways, the dysregulated ribosomerelated genes confer cells to sense or adapt to changes in environmental conditions, including high glucose. ${ }^{28}$ In the current study, RPS4Y1 as a ribosome-related gene was found to be highly expressed in HUVECs under high glucose. In addition, highly expressed RPS4Y1 further activated p38 MAPK signaling to induce dysfunction of HUVECs. It seems that the upregulated RPS4Y1 may be involved in the mechanism of endothelial dysfunction, which we have confirmed in the following in vitro experiments.

Endothelial cells apoptosis and inflammation are the main biochemical characteristics of endothelial dysfunction that can be induced by various stimulations, including oxidative stress, hypoxia, angiotensin II, oxidized low- 


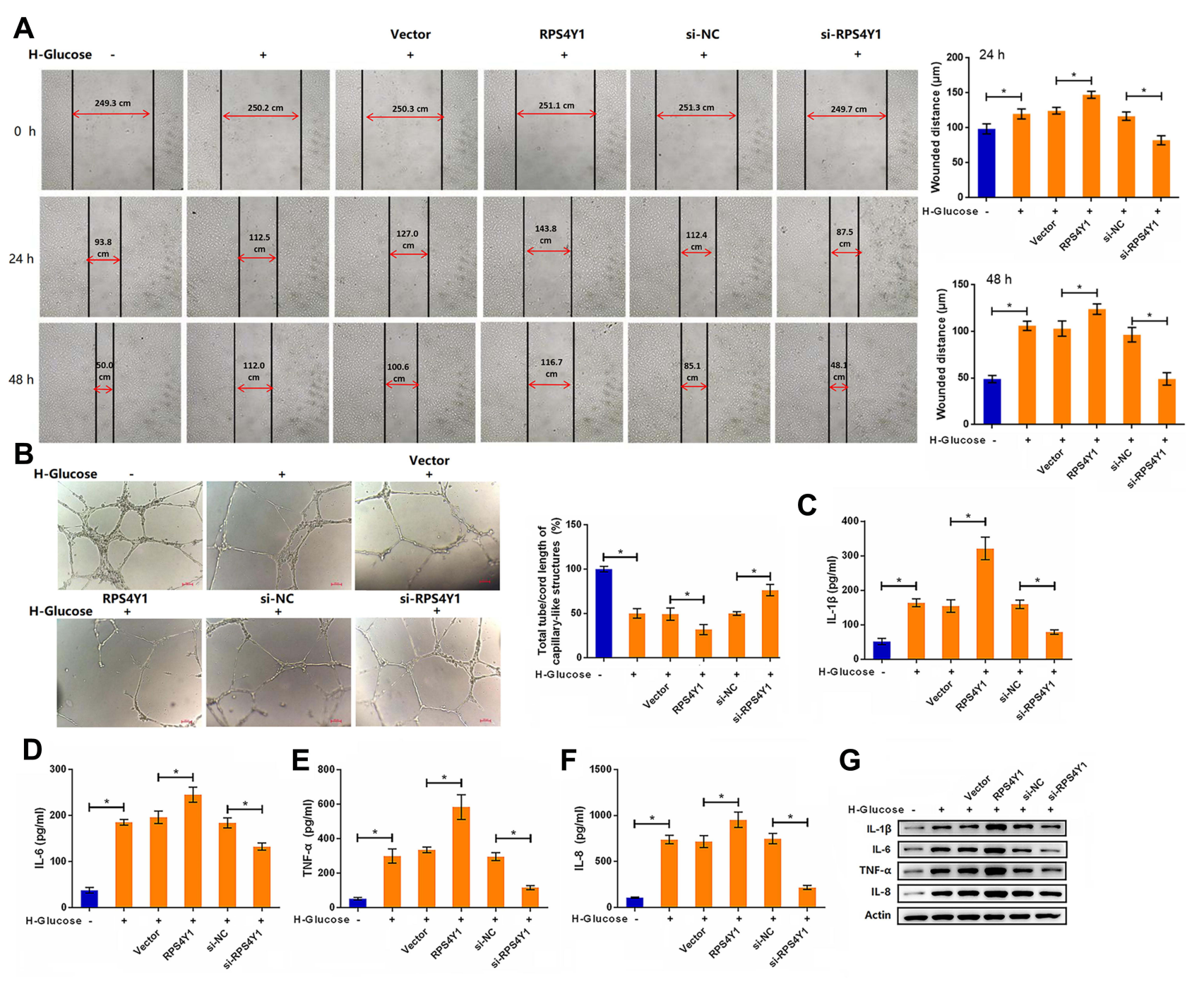

Figure 5 RPS4YI enhanced the dysfunction and inflammation of HUVECs induced by high glucose. HUVECs were transfected with RPS4YI overexpression plasmid, RPS4Y I siRNA or the negative controls (empty vector and si-NC). And then cells were treated by $35 \mathrm{mM}$ glucose for $24 \mathrm{~h}(\mathrm{H}-\mathrm{Glucose}$ group). (A) The migration and (B) tube formation of cells were analyzed by using scratch test and Matrigel gel. (C) IL-I $\beta$, (D) IL-6, (E) TNF- $\alpha$, and (F) IL-8 were analyzed by ELISA. (G) The protein expression of these cytokines was measured by Western blot. ${ }^{*} \mathrm{p}<0.05$ vs the indicated group.

density lipoproteins, and high glucose..$^{29,30}$ In this study, the viability loss of HUVECs induced by high glucose could be accelerated by RPS4Y1 overexpression, while attenuated by RPS4Y1 silence. RPS4Y1 inhibited cell viability possibly by inducing mitochondrial dependent apoptosis, as evidenced by the increase in mitochondrial depolarization. RPS4Y1 contributed to cell death, on the other hand, might be through mediating pro-inflammatory cytokines, including IL- $1 \beta$, IL- 6 , TNF- $\alpha$, and IL-8. In addition, the normal function of endothelial cells, including migration and tube formation, was impaired by RPS4Y1 overexpression, while improved by RPS4Y1 silence. All these results suggested the significant role of RPS4Y1 in endothelial dysfunction. This study is similar to a previous study in which the regulatory function of lncRNA MALAT1 on endothelial cell proliferation, migration, and tube formation was revealed. ${ }^{31}$ However, we for the first time demonstrated RPS4Y1 as one of the mediators in endothelial dysfunction.

MAPK is one of the major signaling pathways that is responsible for transmitting stimulation signals from the cell surface to the nucleus and mediating the subsequent cell response. MAPK comprises three family members, p38, ERK, and Jnk, and all of them are implicated in a wide range of cellular progresses, like proliferation, death, inflammation, differentiation, and stress response. $^{32,33}$ Of note, MAPK signaling is essential for glucose homeostasis. ${ }^{34}$ Patients with diabetes mellitus 
A

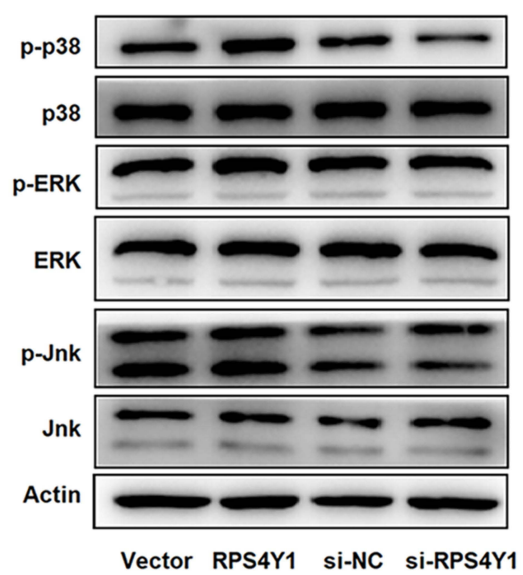

B

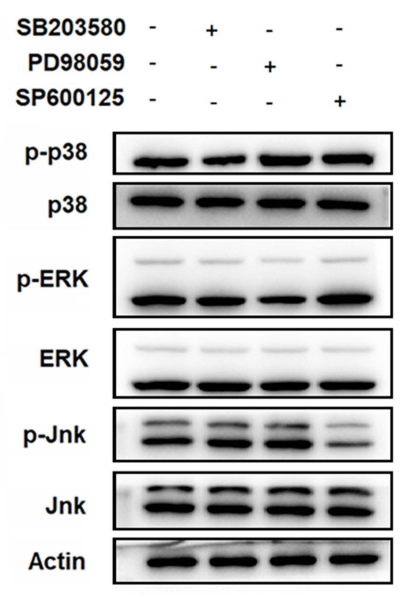

C
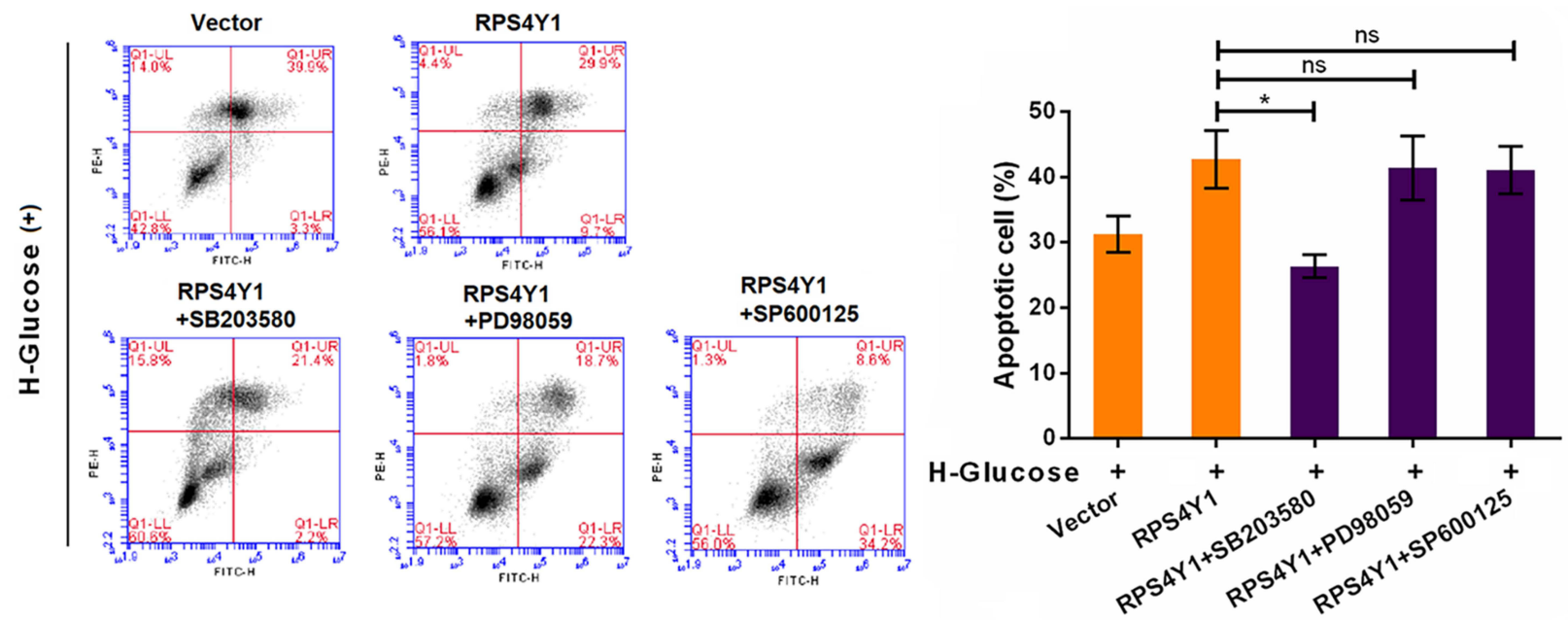

Figure 6 RPS4YI activated p38 MAPK signaling to mediate HUVECs apoptosis and dysfunction. (A) HUVECs were transfected with RPS4YI overexpression plasmid, RPS4YI siRNA or the negative controls (empty vector and si-NC). Protein expression of p38, ERK, Jnk and the corresponding phosphorylated forms was detected by Western blot. (B) HUVECs were treated by $30 \mu \mathrm{M}$ SB203580, $30 \mu \mathrm{M}$ PD98059, or $10 \mu \mathrm{M}$ SP600I25. The expression of P38, ERK, Jnk and the corresponding phosphorylated forms was detected by Western blot. (C) HUVECs transfected with RPS4YI overexpression plasmid or the empty vector were then treated by $35 \mathrm{mM}$ glucose for $24 \mathrm{~h}$ (H-Glucose group). The specific inhibitors of $\mathrm{p} 38$, ERK, and Jnk were then added. Cell apoptosis was detected by flow cytometry; ${ }^{*} \mathrm{p}<0.05 \mathrm{vs}$ the indicated group.

Abbreviation: ns, no significant.

show significant activated MAPK signaling, suggesting MAPK signaling as one key node linking endothelial dysfunction and diabetes mellitus. ${ }^{35-37}$ In addition, p38 is a critical contributor to the regulation of endothelial cell inflammation and apoptosis in response to high glucose. $^{35,38,39}$ Inhibition of p38 signaling activation has been considered to be effective in attenuating endothelial cell dysfunction induced by high glucose. $^{40,41}$ In this study, p38 signaling, rather than ERK and Jnk signaling, was found to be activated by RPS4Y1 in HUVECs. Further in vitro studies for the first time demonstrated that RPS4Y1 contributed to endothelial cell dysfunction, possibly through activation of p38 signaling. The potential mechanism by which RPS4Y1 modulates p38 activity needs to be studied in the future.

\section{Conclusion}

This work showed the upregulated RPS4Y1 expression in HUVECs in response to high glucose. The elevated RPS4Y1 level accelerated high glucose-induced dysfunction of endothelial cells. Additionally, RPS4Y1 
A

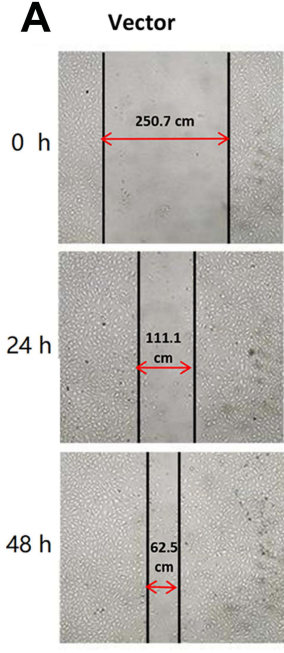

B

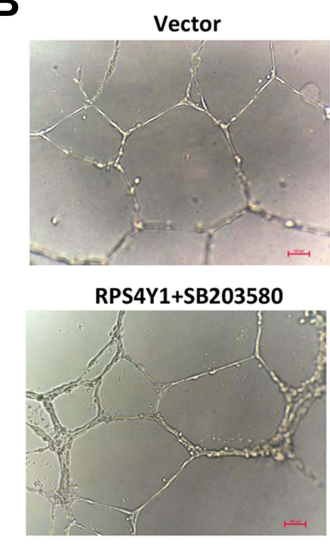

C

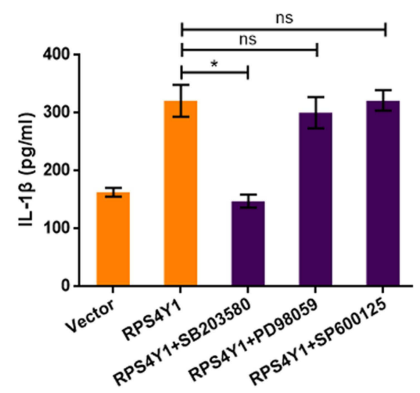

RPS4Y1
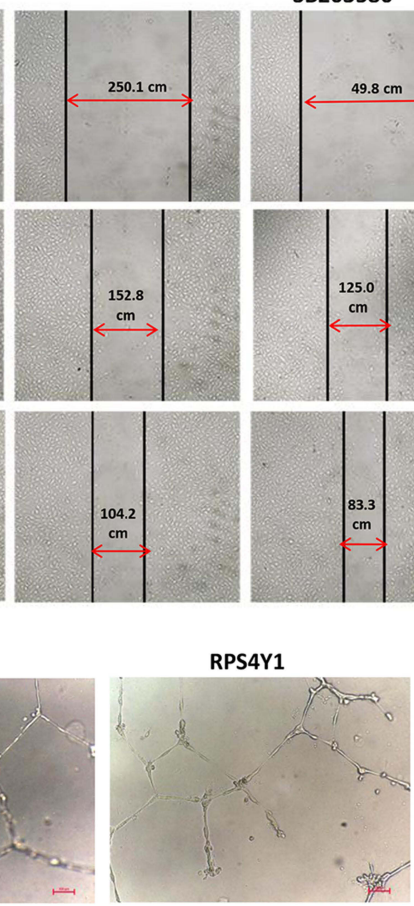

RPS4Y1+PD98059

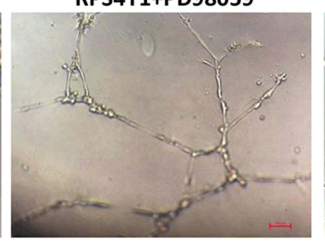

D
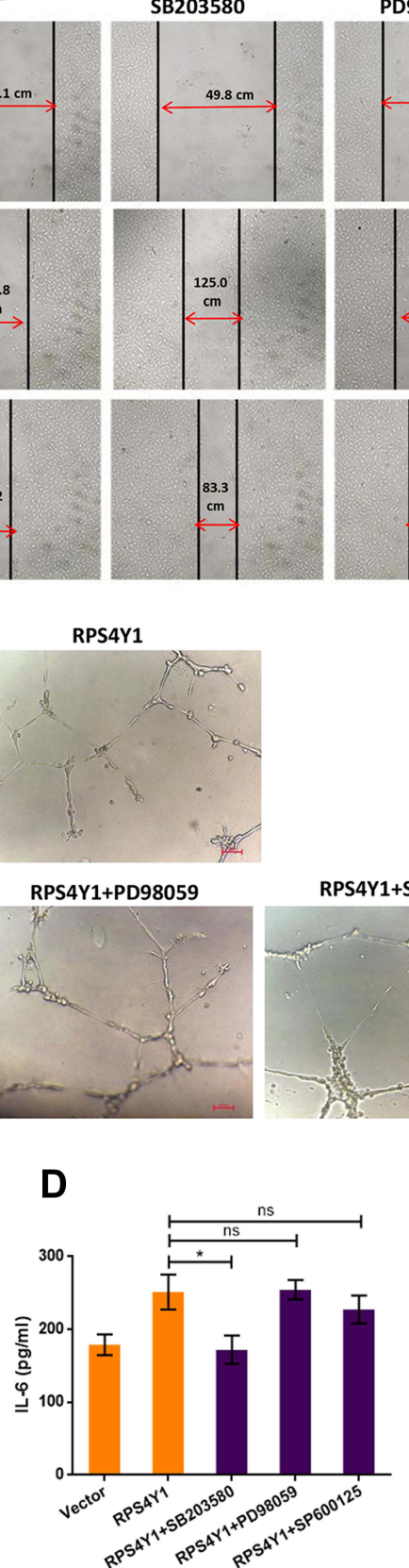

RPS4Y1+

PD98059
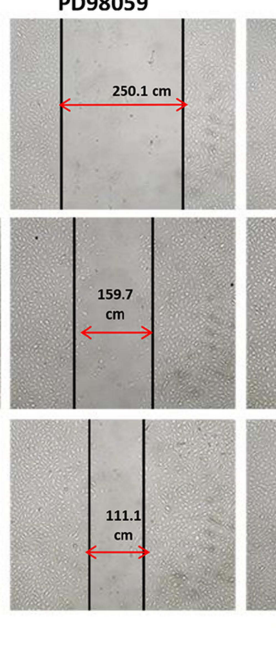

RPS4Y1

SP600125
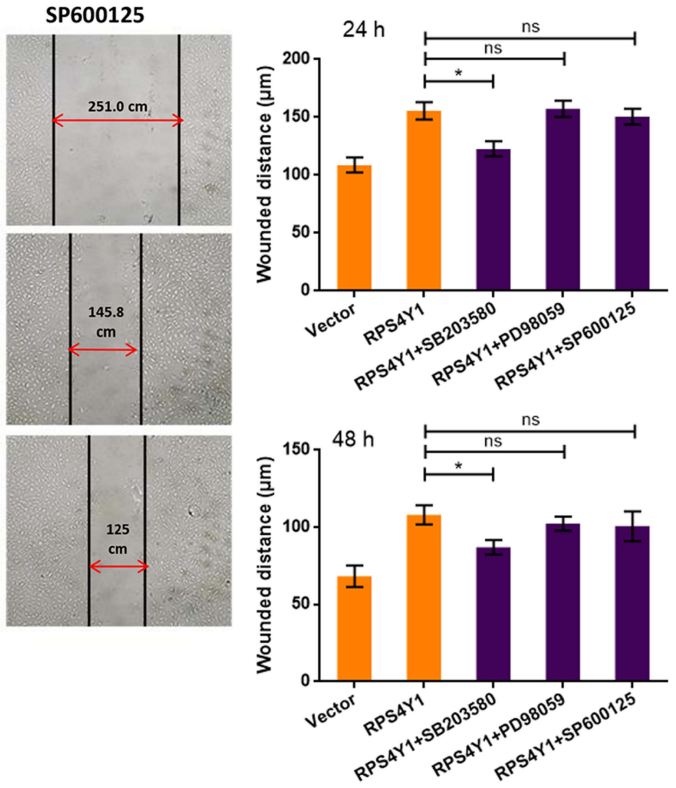

RPS4Y1+SP600125

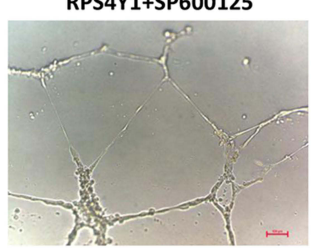

E

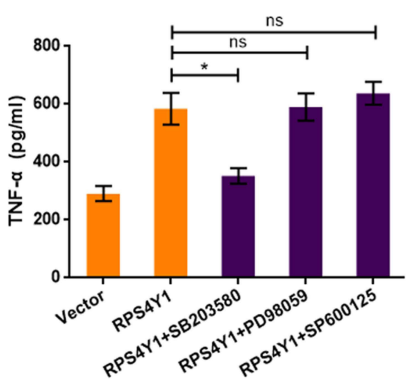

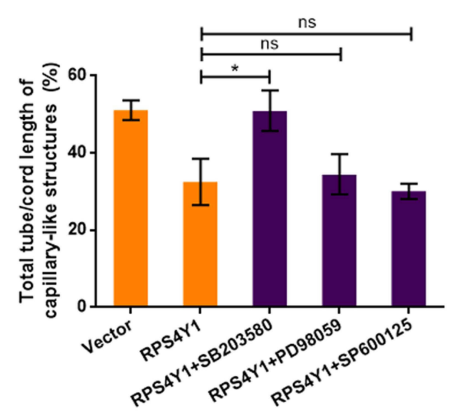

$\mathbf{F}$

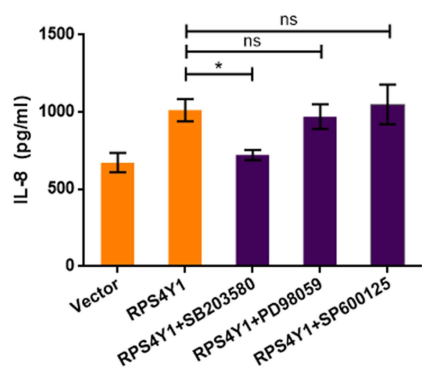

Figure 7 RPS4YI activated P38 MAPK signaling to mediate HUVECs dysfunction and inflammation. HUVECs transfected with RPS4YI overexpression plasmid or the empty vector were then treated by $35 \mathrm{mM}$ glucose for $24 \mathrm{~h}$ ( $\mathrm{H}$-Glucose group). The specific inhibitors of $\mathrm{p} 38$, ERK, and Jnk signaling were then added. (A) Cell migration and (B) tube formation were detected by scratch test and by using Matrigel gel. The concentration of (C) IL-I $\beta$, (D) IL-6, (E) TNF- $\alpha$, and (F) IL-8 were analyzed by ELISA; * $<<0.05$ vs the indicated group.

Abbreviation: ns, no significant.

contributed to endothelial dysfunction, possibly via $\mathrm{p} 38$ MAPK signaling. These findings suggested RPS4Y1 as a potential therapeutic target for treating diabetes mellitus complications.

\section{Data Sharing Statement}

The datasets used and analyzed during the current study are available from the corresponding authors on reasonable requests. 


\section{Ethics Approval and Informed Consent}

Animal and human experiments were not included in this study.

\section{Author Contributions}

All authors made a significant contribution to the work reported, whether that is in the conception, study design, execution, acquisition of data, analysis and interpretation, or in all these areas; took part in drafting, revising or critically reviewing the article; gave final approval of the version to be published; have agreed on the journal to which the article has been submitted; and agree to be accountable for all aspects of the work.

\section{Funding}

This work was supported by National Natural Science Foundation, (Project Approval Number: 81973628); National Natural Science Foundation, (Project Approval Number: 81673793); Ningbo Natural Science Foundation, Role of autophagy-related protein metabolic homeostasis in nerve recovery after craniocerebral injury (Project Approval Number: 2015A610192).

\section{Disclosure}

The authors declare that they have no conflicts of interest in this work.

\section{References}

1. Guariguata L. By the numbers: new estimates from the IDF Diabetes Atlas Update for 2012. Diabetes Res Clin Pract. 2012;98(3):524-525. doi:10.1016/j.diabres.2012.11.006

2. Ashcroft FM, Rorsman P. Diabetes mellitus and the $\beta$ cell: the last ten years. Cell. 2012;148(6):1160-1171. doi:10.1016/j.cell.2012.02.010

3. Alotaibi A, Perry L, Gholizadeh L, Al-Ganmi A. Incidence and prevalence rates of diabetes mellitus in Saudi Arabia: an overview. $J$ Epidemiol Glob Health. 2017;7(4):211-218. doi:10.1016/j. jegh.2017.10.001

4. Brownlee M. The pathobiology of diabetic complications: a unifying mechanism. Diabetes. 2005;54(6):1615-1625. doi:10.2337/ diabetes.54.6.1615

5. Hadi HA, Suwaidi JA. Endothelial dysfunction in diabetes mellitus. Vasc Health Risk Manag. 2007;3(6):853-876.

6. Nagib AM, Elsayed Matter Y, Gheith OA, Refaie AF, Othman NF, AlOtaibi T. Diabetic Nephropathy Following Posttransplant Diabetes Mellitus. Exp Clin Transplant. 2019;17(2):138-146. doi:10.6002/ ect.2018.0157

7. Gui F, You Z, Fu S, Wu H, Zhang Y. Endothelial Dysfunction in Diabetic Retinopathy. Front Endocrinol. 2020;11:591. doi:10.3389/ fendo.2020.00591

8. Knapp M, Tu X, Wu R. Vascular endothelial dysfunction, a major mediator in diabetic cardiomyopathy. Acta Pharmacol Sin. 2019;40 (1):1-8. doi:10.1038/s41401-018-0042-6
9. Andrés O, Kellermann T, López-Giráldez F, Rozas J, DomingoRoura X, Bosch M. RPS4Y gene family evolution in primates. BMC Evol Biol. 2008;8:142. doi:10.1186/1471-2148-8-142

10. Zinn AR, Alagappan RK, Brown LG, Wool I, Page DC. Structure and function of ribosomal protein S4 genes on the human and mouse sex chromosomes. Mol Cell Biol. 1994;14(4):2485-2492.

11. Lambertsson A. The minute genes in Drosophila and their molecular functions. Adv Genet. 1998;38:69-134.

12. Watanabe M, Zinn AR, Page DC, Nishimoto T. Functional equivalence of human X- and Y-encoded isoforms of ribosomal protein S4 consistent with a role in Turner syndrome. Nat Genet. 1993;4 (3):268-271. doi:10.1038/ng0793-268

13. Chen X, Tong C, Li H, et al. Dysregulated Expression of RPS4Y1 (Ribosomal Protein S4, Y-Linked 1) Impairs STAT3 (Signal Transducer and Activator of Transcription 3) Signaling to Suppress Trophoblast Cell Migration and Invasion in Preeclampsia. Hypertension. 2018;71(3):481-490. doi:10.1161/HYPERTENSION AHA.117.10250

14. Holland OJ, Linscheid C, Hodes HC, et al. Minor histocompatibility antigens are expressed in syncytiotrophoblast and trophoblast debris: implications for maternal alloreactivity to the fetus. Am J Pathol. 2012;180(1):256-266. doi:10.1016/j.ajpath.2011.09.021

15. Palmer AK, Tchkonia T, LeBrasseur NK, Chini EN, Xu M, Kirkland JL. Cellular Senescence in Type 2 Diabetes: a Therapeutic Opportunity. Diabetes. 2015;64(7):2289-2298. doi:10.2337/db14-1820

16. Shenouda SM, Widlansky ME, Chen K, et al. Altered mitochondrial dynamics contributes to endothelial dysfunction in diabetes mellitus. Circulation. 2011;124(4):444-453. doi:10.1161/CIRCULATIONA HA. 110.014506

17. Sedeek M, Callera G, Montezano A, et al. Critical role of Nox4-based NADPH oxidase in glucose-induced oxidative stress in the kidney: implications in type 2 diabetic nephropathy. Am J Physiol Renal Physiol. 2010;299(6):F1348-1358. doi:10.1152/ajprenal.00 028.2010

18. Uchiba M, Okajima K, Oike $\mathrm{Y}$, et al. Activated protein $\mathrm{C}$ induces endothelial cell proliferation by mitogen-activated protein kinase activation in vitro and angiogenesis in vivo. Circ Res. 2004;95 (1):34-41. doi:10.1161/01.RES.0000133680.87668.FA

19. Pearson G, Robinson F, Beers Gibson T, et al. Mitogen-activated protein (MAP) kinase pathways: regulation and physiological functions. Endocr Rev. 2001;22(2):153-183.

20. Schmidt AM. Highlighting Diabetes Mellitus: the Epidemic Continues. Arterioscler Thromb Vasc Biol. 2018;38(1):e1-e8. doi:10.1161/ATVBAHA.117.310221

21. Halvorsen B, Santilli F, Scholz H, et al. LIGHT/TNFSF14 is increased in patients with type 2 diabetes mellitus and promotes islet cell dysfunction and endothelial cell inflammation in vitro. Diabetologia . 2016;59(10):2134-2144. doi:10.1007/s00125-0164036-y

22. Lam YW, Lamond AI, Mann M, Andersen JS. Analysis of nucleolar protein dynamics reveals the nuclear degradation of ribosomal proteins. Curr Biol. 2007;17(9):749-760. doi:10.1016/j. cub.2007.03.064

23. Sung MK, Porras-Yakushi TR, Reitsma JM, et al. A conserved quality-control pathway that mediates degradation of unassembled ribosomal proteins. Elife. 2016;5:19101.

24. Shenoy N, Kessel R, Bhagat TD, et al. Alterations in the ribosomal machinery in cancer and hematologic disorders. J Hematol Oncol. 2012;5:32. doi:10.1186/1756-8722-5-32

25. Yang F, Lu X, Zong H, Ji H, Zhuge B. Gene expression profiles of Candida glycerinogenes under combined heat and high-glucose stresses. J Biosci Bioeng. 2018;126(4):464-469. doi:10.1016/j. jbiosc.2018.04.006

26. Dong J, Liao W, Peh HY, et al. Ribosomal protein S3 gene silencing protects against experimental allergic asthma. Br J Pharmacol. 2017;174(7):540-552. doi:10.1111/bph.13717 
27. Dai MS, Sears R, Lu H. Feedback regulation of c-Myc by ribosomal protein L11. Cell Cycle. 2007;6(22):2735-2741. doi:10.4161/ cc.6.22.4895

28. Mancio-Silva L, Slavic K, Grilo Ruivo MT, et al. Nutrient sensing modulates malaria parasite virulence. Nature. 2017;547 (7662):213-216. doi:10.1038/nature23009

29. Choy JC, Granville DJ, Hunt DW, McManus BM. Endothelial cell apoptosis: biochemical characteristics and potential implications for atherosclerosis. J Mol Cell Cardiol. 2001;33(9):1673-1690. doi:10.1006/jmcc.2001.1419

30. Dalan R, Liu X, Goh LL, Bing S, Luo KQ. Endothelial cell apoptosis correlates with low haptoglobin concentrations in diabetes. Diab Vasc Dis Res. 2017;14(6):534-539. doi:10.1177/ 1479164117719827

31. Liu JY, Yao J, Li XM, et al. Pathogenic role of 1ncRNA-MALAT1 in endothelial cell dysfunction in diabetes mellitus. Cell Death Dis. 2014;5(10):e1506. doi:10.1038/cddis.2014.466

32. Chang L, Karin M. Mammalian MAP kinase signalling cascades. Nature. 2001;410(6824):37-40. doi:10.1038/35065000

33. Taylor CA, Zheng Q, Liu Z, Thompson JE. Role of p38 and JNK MAPK signaling pathways and tumor suppressor p53 on induction of apoptosis in response to Ad-eIF5A1 in A549 lung cancer cells. Mol Cancer. 2013;12:35. doi:10.1186/1476-4598-12-35

34. Schultze SM, Hemmings BA, Niessen M, Tschopp O. PI3K/AKT, MAPK and AMPK signalling: protein kinases in glucose homeostasis. Expert Rev Mol Med. 2012;14:e1. doi:10.1017/ S1462399411002109
35. Liu Z, Cao W. p38 mitogen-activated protein kinase: a critical node linking insulin resistance and cardiovascular diseases in type 2 diabetes mellitus. Endocr Metab Immune Disord Drug Targets. 2009;9 (1):38-46. doi:10.2174/187153009787582397

36. Xu Z, Sun J, Tong Q, et al. The Role of ERK1/2 in the Development of Diabetic Cardiomyopathy. Int J Mol Sci. 2016;17:12. doi:10.3390/ ijms 17122001

37. Wu JJ, Roth RJ, Anderson EJ, et al. Mice lacking MAP kinase phosphatase-1 have enhanced MAP kinase activity and resistance to diet-induced obesity. Cell Metab. 2006;4(1):61-73. doi:10.1016/j. cmet.2006.05.010

38. Corre I, Paris F, Huot J. The p38 pathway, a major pleiotropic cascade that transduces stress and metastatic signals in endothelial cells. Oncotarget. 2017;8(33):55684-55714. doi:10.18632/oncotarget.18264

39. Takaishi H, Taniguchi T, Takahashi A, Ishikawa Y, Yokoyama M. High glucose accelerates MCP-1 production via p38 MAPK in vascular endothelial cells. Biochem Biophys Res Commun. 2003;305 (1):122-128. doi:10.1016/S0006-291X(03)00712-5

40. Nakagami H, Morishita R, Yamamoto K, et al. Phosphorylation of p38 mitogen-activated protein kinase downstream of bax-caspase-3 pathway leads to cell death induced by high D-glucose in human endothelial cells. Diabetes. 2001;50(6):1472-1481. doi:10.2337/diabetes.50.6.1472

41. Kim SW, Kim CE, Kim MH. Flavonoids inhibit high glucose-induced up-regulation of ICAM-1 via the p38 MAPK pathway in human vein endothelial cells. Biochem Biophys Res Commun. 2011;415(4):602-607. doi:10.1016/j.bbrc.2011.10.115

\section{Publish your work in this journal}

Diabetes, Metabolic Syndrome and Obesity: Targets and Therapy is an international, peer-reviewed open-access journal committed to the rapid publication of the latest laboratory and clinical findings in the fields of diabetes, metabolic syndrome and obesity research. Original research, review, case reports, hypothesis formation, expert opinion and commentaries are all considered for publication. The manuscript management system is completely online and includes a very quick and fair peer-review system, which is all easy to use. Visit http://www.dovepress.com/testimonials.php to read real quotes from published authors. 